\title{
Indicators of the Sustainability of Historical Tourism of Communities Surrounding Phra Nakorn Sri Ayutthaya Historical Park
}

\author{
Somchai Seviset ${ }^{1}$ and Sittichai Charoensettasilp ${ }^{2, *}$ \\ ${ }^{1}$ Department of Architectural Education and Design, Faculty of Industrial Education and Technology, Bangkok, Thailand \\ ${ }^{2}$ Department of Applied Statistics, Faculty of Science, King Mongkut's Institute of Technology Ladkrabang, Bangkok, Thailand \\ *Corresponding author
}

\begin{abstract}
Due to objectives of the research on studying behaviors, level of knowledge of people and analysis of indicators affecting the sustainability of historical tourism in communities surrounding Phra Nakaorn Sri Ayutthaya Historical Park. Questionnaire and interviews are used as research instruments in collecting data, leader of each community and people in communities surrounding Phra Nakorn Sri Ayutthaya are population in this research and both Qualitative Research and Quantitative Research are used in term of Structural Equation Model. Due to studying behaviors of people communities, it is found that participating behavior in implementation and operation has Most Mean, followed by presentation of opinions, planning and decision, monitoring and evaluation and sharing benefits respectively. Due to studying level of knowledge in community, it is found that people in communities have knowledge in locations and history in Good Mean and knowledge in OTOP is in Intermediate Mean. In part of level of knowledge of external community, it is found that people in communities have knowledge in tourist's behavior and communications in Good Level and knowledge in English is in Low Level. The analysis of indicators of the sustainability of historical tourism indicates that participating behaviors of people in communities affecting directly to development of tourism, followed by internal knowledge, internal and external indicators of tourism and external knowledge respectively. If it is considered detail of participating behaviors in operation and implementation, it is found that participation in safety is in Least Level, followed by implementation between people in communities and government and private sectors, public relations in providing tourism information, concurrent implementation with municipality, cleanliness and beauty of tourist attractions and compliance with regulations or measures in supervision of communities respectively.
\end{abstract}

Keywords-historical Tourism; Phra Nakorn Sri ayutthaya historical park; indicators of tourism

\section{INTRODUCTION}

The proportion of current domestic tourism of Thai people increases due to promotional campaigns of government sector and related directly organization such as Tourism Authority of Thailand which constitute economic benefits, earning income and distribution of income in every provinces. However, there are some situations caused by both internal factors and external factors which may affect tourism of domestic tourists and traveling for tourism. Researcher is interested in studying behaviors and level of knowledge of people in communities surrounding Phra Nakorn Sri Ayutthaya Historical Park which affect the sustainability of historical tourism as well as analysis of indicators which affect the sustainability of historical tourism and leading to suggestion of guidelines in development or planning for the understandable co-existence in order to constitute perception and passion of historical sites as well as values of both concrete and abstract forms of cultures and development of the sustainability of historical tourism. Information obtained from this research will be used in development, improvement and changing strategies of marketing communications efficiently in order to respond the various forms of tourist's requirements which constitute more distribution of internal income which leads to the national growth. Therefore, cultural tourism related to the important historical, arts and cultural locations and landscapes, changes regularly, it requires abreast of context and era by planning in development and providing knowledge and experiences in tourism which can maintain and creating the existence of beauty value, systematical change. The development of knowledge in the sustainability of historical tourism will be consistent and suitable for changing society where new innovations, technologies, social system and social values are well combined which affects to perception and passion as well as values of both concrete and abstract forms of the sustainability of historical cultures.

\section{OBJECTIVES OF RESEARCH}

1. Studying behaviors of people in communities surrounding Phra Nakorn Sri Ayutthaya Historical Park which affect the sustainability of historical tourism.

2. Studying level of knowledge of the sustainability of historical tourism of communities surrounding Phra Nakorn Sri Ayutthaya Historical Park.

3. Analysis of indicators which affect the sustainability of historical tourism. 


\section{ReSEARCH Methodology}

\section{A. Population and Sample}

Population is leaders and people in communities surrounding Phra Nakorn Sri Ayutthaya Historical Park totally 2,784 persons. Sample is leaders and people in communities surrounding Phra Nakorn Sri Ayutthaya Historical Park totally 362 persons.

\section{B. Research Instruments}

In this research, Researcher has designed research instruments as follow:

Interview is an instrument used in interviewing information regarding perception of information and knowledge of historical tourism. Questionnaire is an instrument used in collecting opinions of people in communities surrounding Phra Nakorn Sri Ayutthaya Historical Park.

\section{Data Analysis}

Data collected from the interview of communities' leaders and people in communities surrounding Phra Nakorn Sri Ayutthaya Historical Park will be analyzed separately as follow: Descriptive Statistics is used in analysis of fundamental data such as Mean, Standard Deviation, priority and interpretation is made by description and Mean has the meaning in 5 ranges of scores. Inference Statistics used in conclusion of population is called Structural Equation Model [1].

In conclusion and interpretation of data obtained from the interview, Qualitative Analysis is used by Content Analysis Method [2].

\section{Results of DAta ANALYsis}

Due to studying behaviors of people in communities which affect the sustainability of historical tourism of communities surrounding Phra Nakorn Sri Ayutthaya Historical Park as indicated in Table 1

TABLE I. PARTICIPATING BEHAVIORS OF PEOPLE IN COMMUNITIES SURROUNDING PHRA NAKORN SRI AYUTTHAYA HISTORICAL PARK

\begin{tabular}{|c|c|c|}
\hline Participating Behaviors & Mean $(\overline{\mathrm{x}})$ & Rank \\
\hline Presentation of opinions, planning and decision & 2.71 & 2 \\
\hline Implementation and operation & 2.86 & 1 \\
\hline Sharing benefits & 2.14 & 4 \\
\hline Monitoring and evaluation & 2.37 & 3 \\
\hline
\end{tabular}

From Table 1 Participating Behaviors, it is found that people in communities participate in implementation and operation in most level, Mean is 2.86 , followed by presentation of opinions, planning and decision, Mean is 2.71 and followed by monitoring and evaluation, Mean is 2.37 and least level is sharing benefits, Mean is 2.14 .

Due to studying perception of information and knowledge of the sustainable historical tourism of communities surrounding Phra Nakorn Sri Ayutthaya Historical Park which is consisted of internal knowledge and external knowledge of communities, results of analysis are indicated in Table 2.
TABLE II. LEVEL OF INTERNAL KNOWLEDGE AND EXTERNAL KNOWLEDGE OF PEOPLE IN COMMUNITIES SURROUNDING PHRA NAKORN SRI AYUTTHAYA HISTORICAL PARK (FULL SCORE IS 4)

\begin{tabular}{|c|c|c|c|}
\hline Knowledge & Mean $(\overline{\mathrm{x}})$ & Percentage & Rank \\
\hline Internal Community & & & \\
\hline Locations & 3.2943 & 82.36 & 1 \\
\hline History & 2.8257 & 70.64 & 2 \\
\hline OTOP & 2.3486 & 58.72 & 3 \\
\hline External Community & & & \\
\hline Tourist's behavior & 3.0114 & 75.29 & 1 \\
\hline Communication & 2.8143 & 70.36 & 2 \\
\hline Language & 1.3429 & 33.57 & 3 \\
\hline
\end{tabular}

From Table 2 Knowledge of people in communities regarding internal community, it is found that people in communities have knowledges of locations and history in good level, Mean is 3.2943 and 2.8257 respectively which is calculated as $82.36 \%$ and $70.64 \%$ respectively. Knowledge in OTOP is intermediate level, Mean is 2.3486 which is calculated as $58.72 \%$. In part of External Community, it is found that people in communities have knowledge in tourist's behavior and communication in good level, Mean is 3.0114 and 2.8143 respectively which is calculated as $75.29 \%$ and $70.36 \%$ respectively and knowledge in language in low level, Mean is 1.3429 which is calculated as $33.57 \%$.

Due to studying indicated factors affect the sustainability of historical tourism of communications surrounding Phra Nakorn Sri Ayutthaya Historical Park which are consisted of knowledge of internal community (KI), knowledge of external community (KE), Indicators of internal tourism (II), Indicators of external tourism (IE), Participation of people in communities (P) in order to develop Structural Equation Model (SEM) by using AMOS Program and conceptual framework can be prepared before conducting analysis of Structural Equation Model as shown in Figure 1.

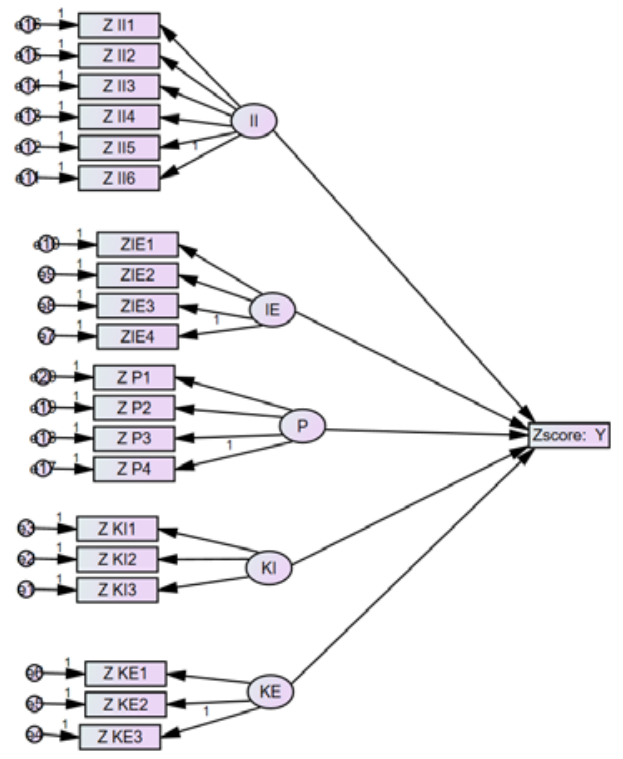

FIGURE I. CONCEPTUAL FRAMEWORK BEFORE ANALYSIS OF STRUCTURAL EQUATION MODEL IN ORDER TO INSPECT INDICATORS WHICH AFFECT THE SUSTAINABILITY OF HISTORICAL TOURISM OF COMMUNITIES SURROUNDING PHRA NAKORN SRI AYUTTHAYA HISTORICAL PARK 
Due to the analysis of Structural Equation Model (SEM) of Indicators which affect the Sustainability of Historical Tourism of Communities Surrounding Phra Nakorn Sri Ayutthaya Historical Park is shown in Figure 2.

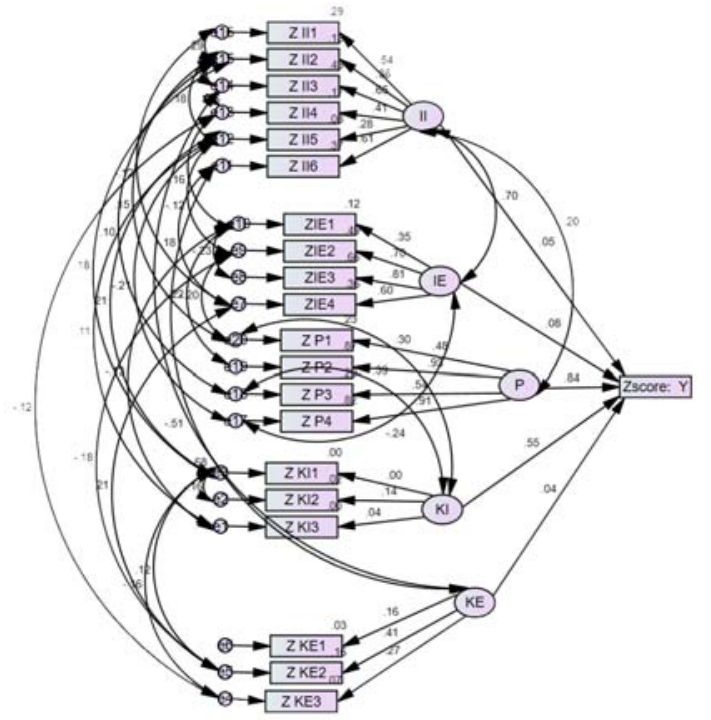

FIGURE II. STRUCTURAL EQUATION MODEL (SEM) AFTER ANALYSIS OF INDICATORS WHICH AFFECT THE SUSTAINABILITY OF HISTORICAL TOURISM OF COMMUNITIES SURROUNDING PHRA NAKORN SRI AYUTTHAYA HISTORICAL PARK

Due to results of Causal Relationship Model, Development of tourism of people in communities (Y) is consisted of knowledge of internal community (KI), knowledge of external community (KE), indicators of internal tourism (II), indicators of external tourism (IE), Participation of people in communities (P). Participation of people in communities has positive influence directly to development of tourism of people in communities in most level which has Standardized Estimates 0.84 , followed by knowledge of internal community which has Standardized Estimates 0.55, indicators of external tourism which has Standardized Estimates 0.08, indicators of internal tourism which has Standardized Estimates 0.05 and knowledge of external community which has Standardized Estimates 0.04 respectively. In part of participation of people in communities $(\mathrm{P})$ which is consisted of participation in presentation of opinions, planning and decision (P1), implementation and operation (P2), sharing benefits (P3) and monitoring and evaluation (P4), it is found that participation in implementation and operation have positive influence directly to participation of people in communities in most level which has Standardized Estimates 0.93, followed by monitoring and evaluation which have Standardized Estimates 0.91, sharing benefits evaluation which have Standardized Estimates 0.54 and presentation of opinions, planning and decision which have Standardized Estimates 0.48 respectively. In part of knowledge of internal community (KI) which is consisted of knowledge of locations (KI1), knowledge of history (KI2) and knowledge of OTOP (KI3), it is found that knowledge of history has positive influence directly to knowledge of internal community in most level which has Standardized Estimates 0.14, followed by knowledge of locations which has Standardized Estimates 0.04 and knowledge of OTOP which has Standardized Estimates 0.003 respectively. In part of indicators of external tourism (IE) which is consisted of economic and political situations (IE1), value of tourism (IE2), expansion of communication (IE3) and changing of political policy (IE4), it is found that expansion of communication has positive influence directly to indicators of external tourism in most level which has Standardized Estimates 0.81 , followed by value of tourism which has Standardized Estimates 0.70, changing of political policy which has Standardized Estimates 0.60 and economic and political situations which have Standardized Estimates 0.35 respectively. In part of indicators of internal tourism (II) which is consisted of tourism resources (II1), safety (II2), facilitations (II3), souvenirs (II4), advertisement and public relations (II5) and image (II6), it is found that facilitations have positive influence directly to indicators of external tourism in most level which has Standardized Estimates 0.65 , followed by image which has Standardized Estimates 0.61, internal tourism has Standardized Estimates 0.54, souvenirs has Standardized Estimates 0.41, safety has Standardized Estimates 0.36 and advertisement and public relations which have Standardized Estimates 0.28 respectively. In part of knowledge of external community (KE) which is consisted of knowledge of tourist's behavior (KE1), knowledge of communication (KE2) and knowledge of language (KE3), it is found that knowledge of communication has positive influence directly to knowledge of external community in most level which has Standardized Estimates 0.41, followed by knowledge of language which has Standardizes Estimates 0.27 and knowledge of tourist's behavior which has Standardized Estimates 0.16 respectively.

Due to analysis of Causal Relationship Model in overview, it is found that participation of people in communities affect directly to development of tourism in most level as indicated in Table 3

TABLE III. LEVEL OF INTERNAL KNOWLEDGE AND EXTERNAL KNOWLEDGE OF PEOPLE IN COMMUNITIES SURROUNDING PHRA NAKORN SRI AYUTTHAYA HISTORICAL PARK (FULL SCORE IS 4)

\begin{tabular}{|l|l|l|}
\hline Implementation and Operation & Mean $(\overline{\mathrm{x}})$ & Rank \\
\hline Concurrent implementation with Municipality & 2.91 & 3 \\
\hline $\begin{array}{l}\text { Implementation between people in communities } \\
\text { and government sector and private sector }\end{array}$ & 2.59 & 5 \\
\hline $\begin{array}{l}\text { Compliance with regulations or measures in } \\
\text { Supervision of communities }\end{array}$ & 3.29 & 1 \\
\hline $\begin{array}{l}\text { Maintaining cleanliness and beauty of tourist } \\
\text { attraction }\end{array}$ & 3.05 & 2 \\
\hline Maintaining safety & 2.52 & 6 \\
\hline $\begin{array}{l}\text { Public relations and providing tourism } \\
\text { information }\end{array}$ & 2.81 & 4 \\
\hline
\end{tabular}

From Table 3, it is found that participation in maintaining safety has least Mean, followed by implementation between people in communities with government sector and private sector, followed by public relations and providing tourism information, concurrent implementation with Municipality, maintaining cleanliness and beauty of tourist attractions and compliance with regulation and measures in supervision of communities respectively. 


\section{CONCLUSION}

Due to studying behaviors of people in communities, it is found that participating behaviors in implementation and operation has Most Mean, followed by presentation of opinions, planning and decision, monitoring and evaluation and sharing benefits respectively. Due to studying level of knowledge of the sustainability of historical tourism or people in communities, in part of level of knowledge of internal community, it is found that people in communities having knowledge in locations and history in good level, knowledge of OTOP is in intermediate level. In part of level of knowledge of external community, It is found that people in communities having knowledge of tourist's behavior in good level but knowledge in English is in low level. Due to analysis of indicators affecting the sustainability of historical tourism, it is found that the most affected variable is participating behaviors of people in communities, followed by variable of knowledge of internal community, variable of indicators of external tourism, indicators of internal tourism and knowledge of external community respectively. It is also found that participation in maintaining safety having Least Mean, followed by implementation between people in communities and government sector and private sector, public relations and providing tourism information, concurrent implementation with Municipality, maintaining cleanliness and beauty of tourist attractions and compliance with regulations or measures of supervision of communities respectively.

\section{DISCUSSION}

Results and discussion are divided in accordance with 3 objectives of research as researcher will present issues which suitable and consistent to concept applied in research methodology as follow:

1. Results and discussion in accordance with objectives of research 1. Results of research are consistent to theory and research works of Keith [3] as follow: Metal and emotional involvement of any person in group situation. The aforementioned relation is encouraged to achieve objectives of the group by forming responsibilities towards the group likewise. Suriyon Tantrachin [4] Co-perception, co-thinking or co-action in thing which oneself or community may be affected. And Kiatkajorn Watchanasawas [5] Co-requirement, joint-interest to achieve joint-target in economy and society or politics.

2. Due to objectives of research 2. Research results are consistent to theories and research works in Basic Knowledge Management and Application [6] people who resides in tourist attractions in Phra Nakorn Sri Ayutthaya Province for long period of time, experiences will be formulated, therefore, people in such communities have very good knowledge in locations and tourist's behaviors.

3. Due to objective of research 3. Research results are consistent to theories and research works of information obtained from Academic and Training Division, Tourism Authority of Thailand (n.d.) regarding indicators of tourism [7] on Internal Indicators, research results indicate that people in communities emphasizing on facilitations affecting directly to indicators of tourism in most level, followed by tourism resources and souvenirs respectively. In case of external indicators, research results indicate that people in communities emphasizing on expansion of communication which affect directly to indicators of tourism in most level, followed by value of tourism and changing political policy respectively.

\section{REFERENCES}

[1] W.Kanlaya., Structural Equation Modeling Using AMOS, CU Book Center, 2013.

[2] C.Pitsini and S.Pimthong., Qualitative Research, Faculty of Education, Chiangmai University, 2009.

[3] Keith, Davis., Human Behavior of Work-man Relations and Organization Behavior, McGraw-Hell Book Co, New York, 1972.

[4] T.Suriyon., National News Agency Public Relations Department, 2012, om http://thainews.prd.go.th

[5] W.Kiatkajorn.,Criminal Laws, Offences Part Vol. 2. Human Rights Information Technology Center, Thailand, 2007.

[6] V.Pornthida., Basic Knowledge Management and Application. Bangkok: Expernet,2004.

[7] Academic and Training Division, Tourism Authority of Thailand (n.d.). Tourism Industry. Bangkok: Academic Division, Department of Tourism. 